TITLE:

Inauguration Meeting of Mahale Wild life Conservation Society Held at the University of Dar-es-Salaam on August 12, 1994

$\operatorname{AUTHOR}(\mathrm{S})$ :

\title{
CITATION:
}

Inauguration Meeting of Mahale Wild life Conservation Society Held at the University of Dar-es-Salaam on August 12, 1994. Pan Africa News 1995, 2(1): 1-1

ISSUE DATE:

1995-06

URL:

http://hdl.handle.net/2433/143318

RIGHT:

Copyright (C) Pan Africa News. 


\section{Inauguration Meeting of Mahale Wildlife Conservation Society Held at the University of Dar-es-Salaam on August 12, 1994}

The inauguration meeting of the MWCS (Mahale Wildlife Conservation Society) was opened at the University of Dar-es-Salaam at 3:30 pm on the 12th of August 1994. Professor Hosea Y. Kayumbo, Professor Toshisada Nishida and Mr. Toshimichi Nemoto, Chairman, Co-Chairman and Secretary-General of the MWCS, respectively, convened the meeting, which about 20 people attended. The participants included many professors from the University of Dar-es-Salaam, Dr. J. Mitani of the University of Michigan and representatives from the Japanese Embassy and various conservation societies.

The opening address was made by Professor Tambila, followed with speeches by Professors Kayumbo and Nishida. Finally, a complimentary address was made by His Honour, Mr. Msambya, M. P. for Kigoma South. The meeting was closed in a cheerful atmosphere at 5:30 pm.

The Society was officially registered on the 15th of June, 1994 thanks to the efforts of Mr. Rogath Olomi. The speeches by Professors Kayumbo and Nishida are printed in this newsletter.

Editor, through communication with Professor T. Nishida

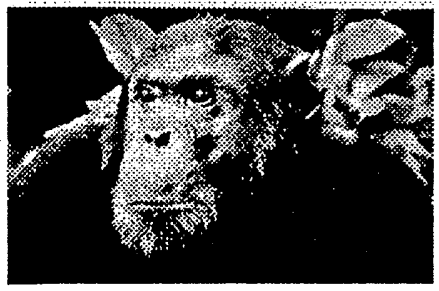

Bembe

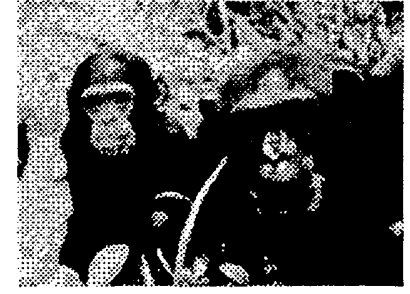

Brutus and his mother, Wakampompo

Photos by Kazuhiko Hosaka

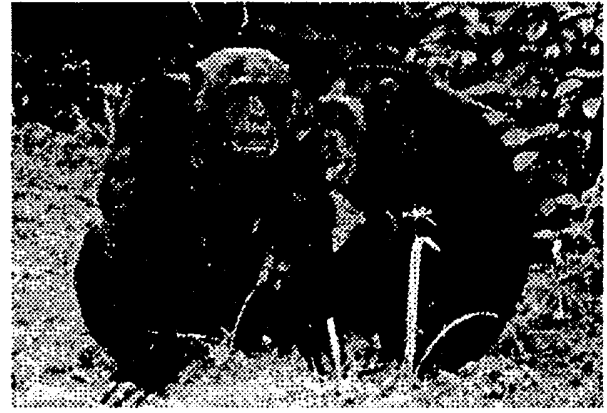

Nsaba and Fanana 